KINETIK, Vol.1, No.3, November 2016, Hal. 123-128

ISSN : 2503-2259,

E-ISSN : 2503-2267

\title{
Perancangan CHATBOT Pusat Informasi Mahasiswa Menggunakan AIML Sebagai Virtual Assistant Berbasis Web
}

\author{
Maskur \\ Universitas Muhammadiyah Malang \\ maskur.informatika@gmail.com
}

\begin{abstract}
Abstrak
Seiring perkembangan teknologi dan keinginan program studi teknik informatika untuk mengembangkan layanan terhadap mahasiswa, informasi yang diperoleh melalui sistem informasi dan chatting yang dilakukan antara pengguna dengan pihak Virtual Assistant. Penelitian ini bertujuan untuk membangun chatbot yang mempunyai tujuan sebagai Virtual Assistant yang memberikan informasi kepada mahasiswa melalui data yang tersimpan pada sistem yang berisi informasi mengenai program studi teknik informatika dan penambahan pengetahuan baru apabila data yang tersimpan tidak ditemukan. Pada perancangan dan implementasi perangkat lunak ini menghasilkan sebuah prototipe Chatbot yang dibangun dengan menggunakan mesin ALICE (Artificial Linguistic Internet Computer Entity) sebagai penerjemah AIML (Artifical Intelligence Markup Language). AIML ini menyebabkan Chatbot dapat mengintegrasikan input yang diterima berupa input text. Sehingga akan dihasilkan percakapan antara pengguna dan program. Dengan pemanfaatan chatbot yang telah dilengkapi dengan informasi berupa audio, membuat pengguna dapat lebih mudah mendapatkan informasi yang berasal dari basis data yang diinformasikan kepada pengguna. Dari hasil pengujian verifikasi, pengujian validitas dan pengujian prototipe yang dilakukan sistem berjalan dengan baik sesuai dengan perencanaan. Dengan pemanfaatan chatbot yang telah dilengkapi dengan kecerdasan buatan, membuat pengguna dapat lebih mudah mendapatkan informasi yang berasal dari basis data yang diinformasikan kepada pengguna secara cepat dengan ketepatan jawaban sekitar $80 \%$.
\end{abstract}

Kata kunci: Chatbot , ALICE, AIML, Virtual Assistant, sistem

\section{Abstract}

As the technology massively developed, IT department desires to improve its service quality for students by utilizing informatic system and chatting using Virtual Assistant. This research aims to develop a chatbot as Virtual Assistant in giving information for students using the recorded data contains of detail information about IT department, and adding option if the data did not match the inquries asked. The design and implementation of this software resulted a Chatbot prototype that is created by using ALICE (Artificial Linguistic Internet Computer Entity) to translate AIML (Artifical Intelligence Markup Language). AIML helps Chatbot to integrate the received input in text form. Thus, the conversation between user and program could possibly happen. By using Chatbot contains of audio data, the user could get the information from the database easier. The verification result shows that the validity and prototype testing of this system are working as expected. Chatbot with artificial intelegence could help the students to get the information they want, with the answer appropriateness up to $80 \%$.

Keywords: Chatbot, ALICE, AIML, Virtual Assistant, system

\section{Pendahuluan}

Seiring perkembangan zaman, secara implikasi menunjang perkembangan teknologi dengan sangat pesat. Informasi adalah salah satu kata kunci pada era globalisasi pada saat ini. Semua aktivitas kehidupan akan memerlukan informasi, sehingga bisa dikatakan bahwa semua aktivitas yang dijalankan dituntut untuk menghasilkan informasi berguna bagi setiap orang. Perkembangan teknologi informasi yang pesat belakangan ini telah memasuki hampir semua bidang kehidupan, hal ini ditandai dengan banyaknya pengguna komputer, baik untuk kepentingan perusahaan atau bisnis sampai kepada hal-hal yang bersifat hiburan, pendidikan dan kesehatan. Program studi Teknik Informatika Universitas Muhammadiyah Malang menggunakan Teknologi Informasi untuk memberikan berbagai informasi kepada mahasiswa 
Teknik Informatika, dengan tujuan agar tidak menimbulkan kerugian waktu yang cukup banyak dalam penyampaian informasi kepada mahasiswa.

Dalam hal ini, peneliti mengimplementasikan pusat informasi kepada mahasiswa Teknik Informatika melalui basis pengetahuan ALICE (Artificial Linguistic Internet Computer Entity) adalah salah satu aplikasi Chatbot yang sedang berkembang saat ini. Basis pengetahuan ALICE Chatbot berbasis AIML (Artifical Intelligence Markup Language). AIML menghasilkan Chatbot dapat mengintegrasikan input yang diterima berupa input dalam bentuk text. Sehingga akan dihasilkan percakapan antara pengguna dan program. Pertanyaan atau input yang dimasukkan akan dilakukan penelusuran di basis data ALICE, apabila tidak ditemukan akan dilakukan proses crawler ke sistem informasi dengan tujuan mencari jawaban yang sesuai dengan pertanyaan yang dimasukkan, kemudian jawaban yang ditemukan akan ditambahkan ke dalam basis data ALICE untuk menambah pengetahuan baru [1].

Pemanfaatan Chatbot yang telah dilengkapi dengan informasi berupa audio, membuat pengguna dapat lebih mudah mendapatkan informasi dari basis data, serta diinformasikan kepada pengguna secara cepat. Penerapan Chatbot sebagai informasi program studi Teknik Informatika menggunakan AIML, diharapkan bisa mempermudah pengguna dalam pencarian informasi yang ada di program studi Teknik Informatika. Pada penelitian [2] menggunakan AIML (Artifical Intelligence Markup Language) di Sistem Informasi PMDFT (Program Magister dan Doktor Fakultas Teknik Universitas Brawijaya), sedangkan penelitian [1] pengembangan ALICE (Artificial Linguistic Internet Computer Entity) menggunakan Chatbot sebagai seorang pakar jaringan komputer.

\section{Metode Penelitian}

\subsection{Pengumpulan dan Analisis Data}

Data untuk Chatbot terdiri dari pengetahuan dasar dalam AIML, penyederhanaan bentuk gramatikal kompleks ke dalam bentuk yang lebih sederhana, pembagian kalimat menjadi sub kalimat, persamaan kata, perbaikan ejaan, dan tata bahasa. Chatbot yang diciptakan dan dibentuk melalui proses dari supervised learning dan ucapan Chatbot sebelumnya [3]. Data dalam penelitian ini merupakan data yang sering diperlukan oleh pengguna. Dalam hal ini, meliputi pencarian informasi mengenai NIDN, NIP, Bidang Minat Dosen, Informasi PKN, dan Informasi Tugas Akhir, serta data crawler diambil dari Sistem Informasi program studi Teknik Informatika, Fakultas Teknik, dan Universitas Muhammadiyah Malang. Pengambilan data ini sebagai bagian untuk membuat dan membentuk kepribadian Chatbot sehingga Chatbot memiliki pengetahuan baru yang ditampilkan pada Tabel 1.

\subsection{Memasukkan Data ke data ALICE.}

Proses normalisasi adalah proses semua input kalimat yang diberikan, dinormalisasikan terlebih dahulu dengan tujuan agar dapat disesuaikan dengan knowledge base yang sesuai dalam bentuk AIML [4].

\section{Substition Normalization}

Merupakan proses input yang berusaha menjaga informasi dari input yang mungkin mengakibatnya akan hilang saat kalimat melewati proses sentence-splitting (pemilahan kalimat) dan pattern-fitting (perubahan pola).

\section{Sentence-Splitting Normalization}

Merupakan proses pemilahan kalimat, yakni memilah kalimat input ke dalam dua kalimat atau lebih. Pemilahan kalimat mendefinisikan tanda yang mengakhiri kalimat setelah substitution telah dilakukan. Dengan acuan bahwa tanda ".,",!",", merupakan batas akhir dari kalimat.

\section{Pattern-Fitting Normaliztion}

Merupakan proses terakhir yang melakukan pengubahan bentuk karakter pada kalimat, menghilangkan tanda baca dalam kalimat input dan mengubah (convert) kalimat input ke dalam huruf capital (uppercase). Tujuan pengubahan dalam bentuk uppercase adalah untuk melakukan proses berikutnya, yakni melakukan pencocokan pola pada pattern AIML yang bentuknya uppercase [3]. 
Tabel 1. Pengetahuan Chatbot

\begin{tabular}{|c|c|c|c|c|}
\hline No & Pattern & Hatpattern & Template & Rekomendasi \\
\hline 1 & Bidang minat & & $\begin{array}{l}\text { 1.Rekayasa Perangkat Lunak. } \\
\text { 2. Jaringan Komputer. 3. Game } \\
\text { Cerdas }\end{array}$ & Bidang Minat \\
\hline 2 & bidang minat & & $<$ srai $>$ bidang minat $</$ srai $>$ & \\
\hline 3 & Bidang minat* & & $<$ srai $>$ bidang minat $</$ srai $>$ & \\
\hline 4 & bidang minat ${ }^{\star}$ & & $<$ srai $>$ bidang minat $</$ srai $>$ & \\
\hline
\end{tabular}

\subsection{Proses Supervised Learning}

Pembelajaran dilakukan oleh Chatbot untuk menambah pengetahuan. Proses iterasi pembelajaran dalam jumlah tertentu akan memperbarui Chatbot, dengan demikian diperlukan sejumlah iterasi pembelajaran yang optimal dan mencapai hasil yang lebih baik.

\subsection{Masukan dari Pengguna}

Pada bagian ini dilakukan pengujian pada Chatbot dengan sejumlah kalimat masukan atau input yang digunakan sudah didefinisikan pada variabe/ penelitian.

\subsection{Hasil Respons dari Chatbot}

Kalimat masukan dari pengguna digunakan untuk mendapatkan respons tentang kepribadian dan pengetahuan yang didapatkan dari proses supervised learning dan ucapan Chatbot atau kalimat masukan pengguna sebelumnya.

\subsection{Pencarian Data pada Sistem Informasi (Menambah Pengetahuan Baru)}

Pencarian data pada website dilakukan apabila data keluaran atau respons dari Chatbot tidak terdapat di dalam data ALICE. Jadi, sistem secara otomatis akan melakukan crawler untuk mencari informasi yang diinginkan oleh pengguna. Pengetahuan baru akan didapatkan dan akan ditambahkan data Chatbot [5].

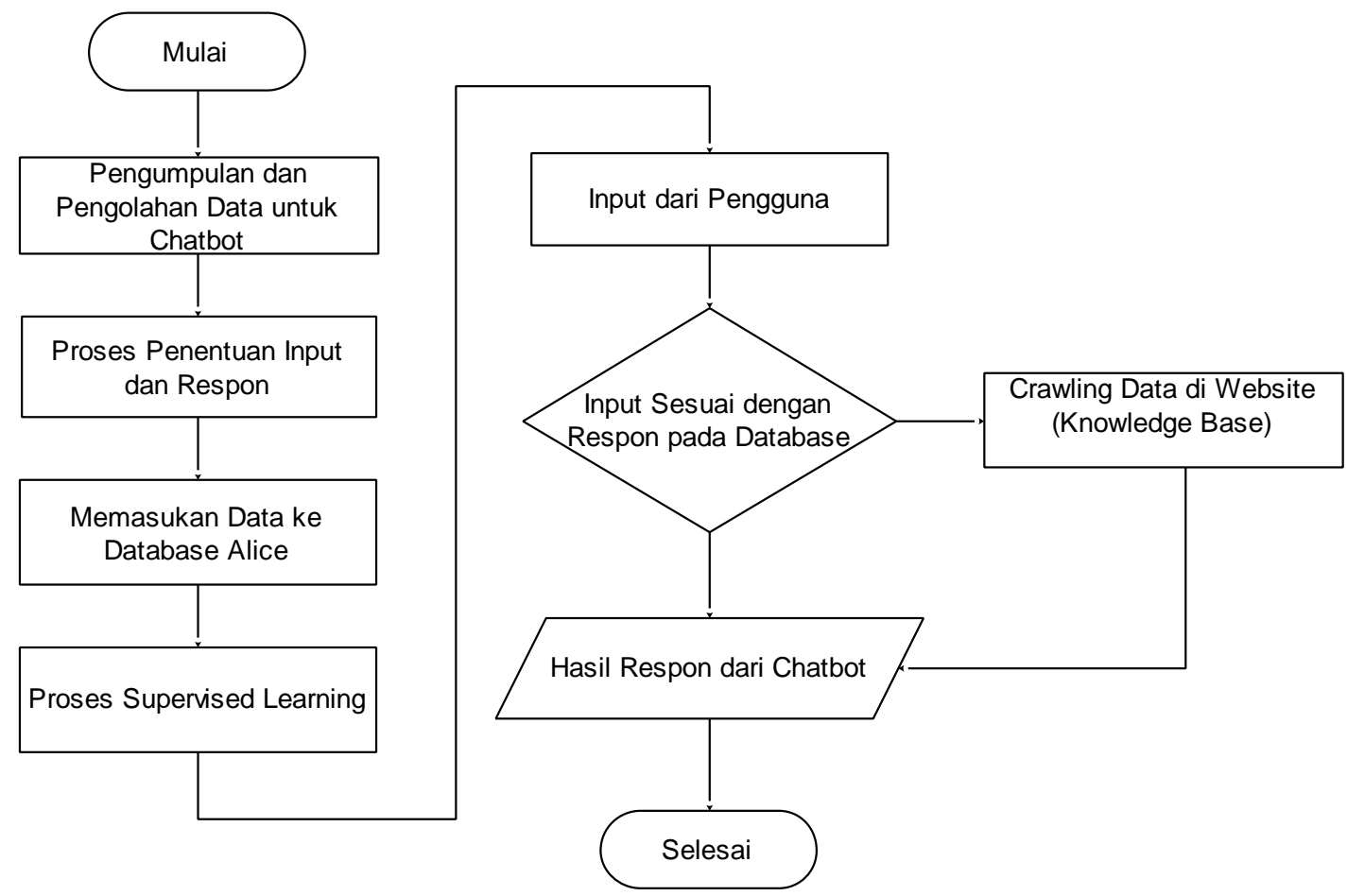

Gambar 1. Flowchart Sistem Chatbot

Untuk mengambil konten dari website (sistem informasi) dengan cara crawler dilakukan apabila data input yang dicari tidak ditemukan pada basis data Chatbot, pengetahuan baru akan dilakukan dan menambahkan ke basis data Chatbot. 


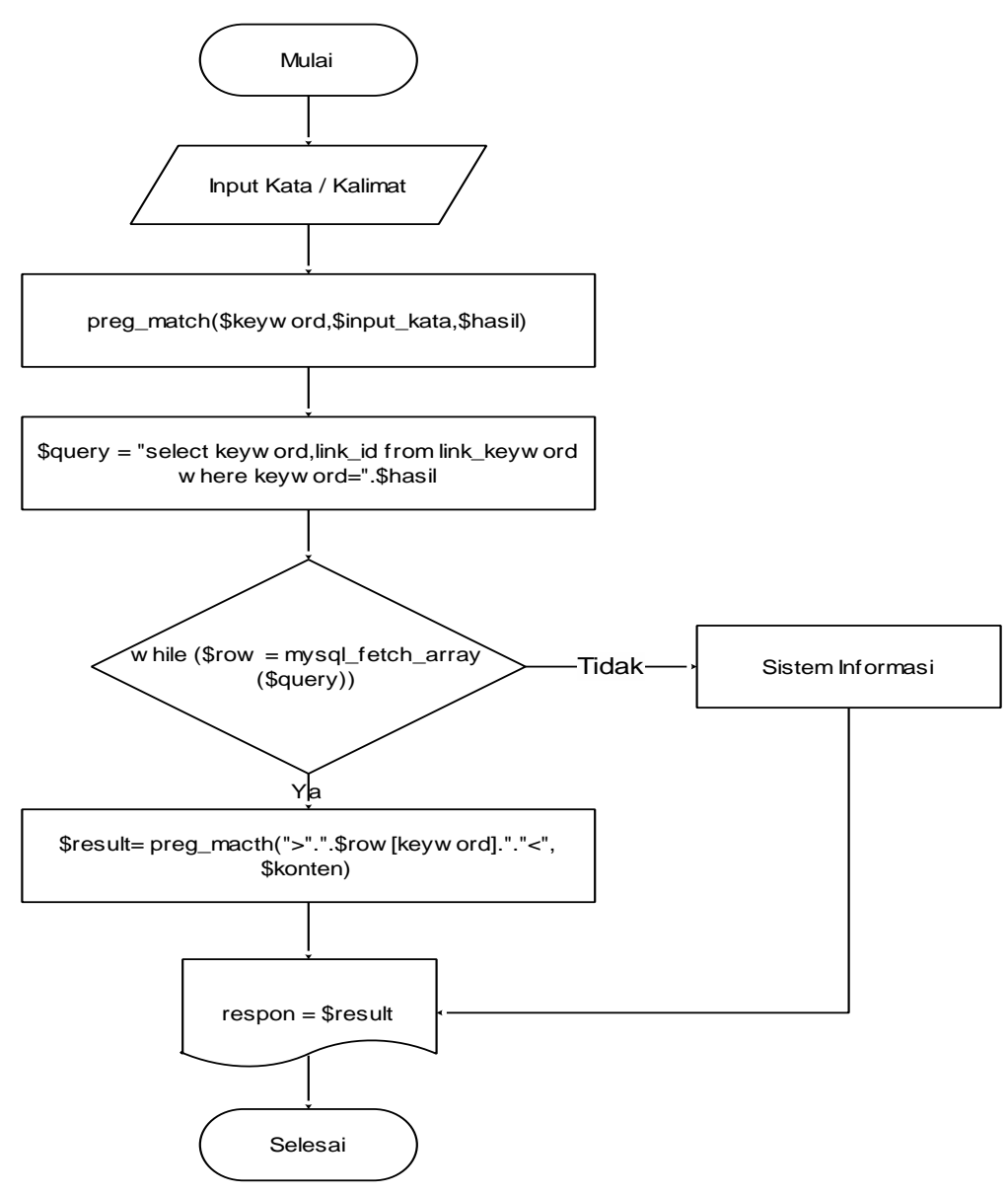

Gambar 2. Flowchart Pengambilan Data dari Konten Website.

Pada Gambar 2 dijelaskan, untuk memberikan gambaran alur proses pengambilan data pada konten website untuk menambah pengetahuan baru pada Chatbot.

1. Pengguna memasukkan kata atau kalimat.

2. Dilakukan proses parsing (proses pengambilan kata atau kalimat berdasarkan pola tertentu) dari masukan yang dimasukkan oleh pengguna. Proses ini berguna untuk mencocokkan apakah masukan yang diberikan oleh pengguna ada pada pengguna ada pada pangkalan data web crawler atau tidak menggunakan fungsi preg_match. Pada halaman website dilakukan proses indexing.

3. Setelah kata atau kalimat dilakukan proses parsing. Hasil parsing tersebut dimasukkan ke dalam query untuk mencari halaman tautan website pada tabel link_keyword.

4. Jika proses query null atau tidak ditemukan, maka proses akan dilanjutkan ke proses pencarian data pada pangkalan data sistem informasi.

5. Dilakukan proses parsing (proses pengambilan kata atau kalimat berdasarkan pola tertentu) dari halaman website yang sudah ditentukan pada proses sebelumnya. Proses ini bertujuan untuk mencocokkan apakah masukan kata atau kalimat dari pengguna ada pada halaman website menggunakan fungsi preg_match.

6. Hasil parsing disimpan pada variabel \$result yang kemudian ditampilkan pada form chat.

\section{Hasil Penelitian dan Pembahasan}

Tahap pengujian merupakan tahap akhir dalam siklus perancangan sistem yang di dalamnya terdapat pengujian validitas, pengujian prototipe dan pengujian fungsionalitas. Jadi, pengujian yang telah dilakukan adalah untuk mengetahui tingkat keberhasilan dari masingmasing tahap pengujian.

\subsection{Pengujian Validasi}

Pengujian validasi merupakan tahap pengujian yang bertujuan untuk melihat atau memeriksa apakah program yang dibuat mampu menghasilkan alternatif keputusan yang 
merepresentasikan tujuan perancangan sistem pendukung keputusan ini. Pada pengujian validasi yang dilakukan adalah melakukan perbandingan hasil dari respons dari Chatbot dengan respons yang diberikan oleh pengguna berdasarkan respons yang diberikan oleh Chatbot dengan menganalisis:

1. Keterkaitan topik antara masukan kata atau kalimat pengguna dengan respons kata atau kalimat yang diberikan Chatbot.

2. Respons kata atau kalimat yang diberikan Chatbot jika informasi yang diinginkan tidak terdapat pada basis data mesin ALICE.

3. Respons kata atau kalimat yang diberikan Chatbot jika informasi yang dinginkan tidak terdapat pada pangkalan data sistem informasi.

4. Respons kata atau kalimat yang diberikan Chatbot, jika masukan atau kalimat tidak berhubungan karakteristik Chatbot, sistem informasi umum dan pengetahuan umum.
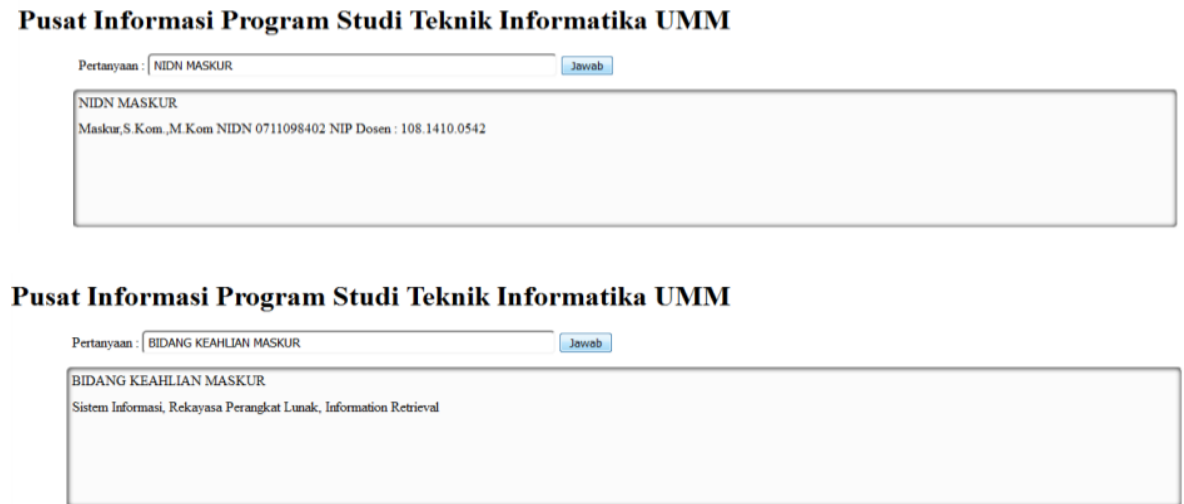

Gambar 3. Implementasi Antarmuka Form Chat.

\subsection{Pengujian Prototipe}

Pengujian prototipe dilakukan dengan tujuan untuk mengetahui apakah prototipe yang dibuat telah memenuhi kebutuhan pengguna atau belum, seperti ditampilkan Gambar 4. Pengujian dilakukan dengan memasukkan pertanyaan mengenai program studi Teknik Informatika, meliputi pertanyaan mengenai Dosen, bidang minat, dan Dosen bidang minat.

\subsubsection{Pengujian Pertanyaan Data Dosen}

Pengujian ini untuk mencari data dosen pada basis data mesin ALICE yang dilakukan pada aplikasi Virtual Assistant ini hasilnya data yang dicari ditemukan.

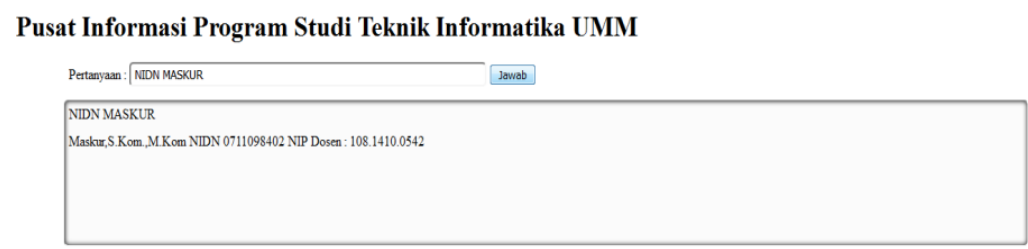

Gambar 4. Pertanyaan Data Dosen.

\subsubsection{Pengujian Pertanyaan Bidang Minat}

Gambar 5, untuk mencari data bidang minat dosen pada mesin ALICE, dilakukan pada aplikasi Virtual Assistant ini hasilnya data yang dicari ditemukan.

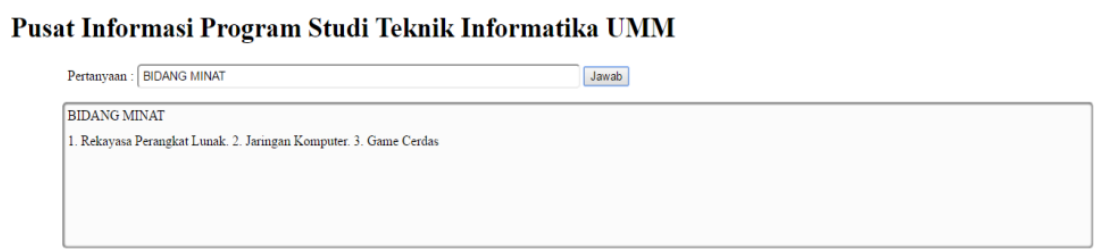

Gambar 5. Pertanyaan Bidang Minat. 


\subsubsection{Pengujian Pertanyaan Nama Dosen Bidang Minat Rekayasa Perangkat Lunak}

Gambar 6, menampilkan baris pengujian untuk mencari data nama dosen bidang minat rekayasa perangkat lunak pada mesin ALICE, dan dilakukan pada aplikasi Virtual Assistant sampai hasil data yang dicari ditemukan.

Pusat Informasi Program Studi Teknik Informatika UMM

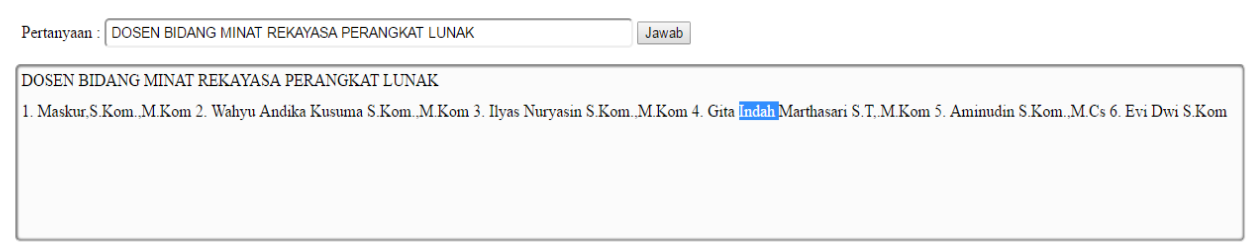

Gambar 6. Pertanyaan Dosen Bidang Minat.

\subsection{Pengujian Fungsional Sistem}

Pada Tabel 2, pengujian fungsional sistem menggunakan metode Blackbox. Pengujian ini merupakan metode pengujian perangkat lunak terhadap fungsionalitas sebuah sistem tanpa melihat logika yang ada dalam sistem tersebut.

Tabel 2. Pengujian Fungsionalitas.

\begin{tabular}{cllc}
\hline Fitur & \multicolumn{1}{c}{ Pengujian } & Gambar & Kesimpulan \\
\hline NIDN Dosen & $\begin{array}{l}\text { Input NIDN Dosen } \\
\text { Input Nama Dosen }\end{array}$ & Gambar 4 & Sesuai \\
\hline $\begin{array}{c}\text { Pilihan Bidang } \\
\text { Minat }\end{array}$ & $\begin{array}{l}\text { Input Bidang Minat } \\
\text { Input Bidang Minat Dosen }\end{array}$ & Gambar 5 & Sesuai \\
\hline $\begin{array}{c}\text { Nama Dosen Per } \\
\text { bidang Minat }\end{array}$ & $\begin{array}{l}\text { Input Dosen Bidang Minat } \\
\text { Perangkat Lunak }\end{array}$ & Gambar 6 & Sesuai \\
\hline
\end{tabular}

\section{Kesimpulan}

Sistem dapat menemukan pertanyaan yang dicari yang ada pada basis data ALICE sesuai pertanyaan yang dimasukkan pengguna. Sistem akan melakukan pencarian pada website sistem informasi dan menambah pengetahuan baru apabila pertanyaan yang dicari tidak ditemukan pada basis data ALICE.

\section{Referensi}

[1] Vrizilia, Arindra. Pengembangan ALICE Sebagai CHATBOT Pakar Jaringan Komputer Menggunakan Supervise (Direct Teaching) dan Unsupervice Learning (Summary Base Knowledge Menggunakan Metode TF-IDF). Malang: Universitas Muhammadiyah Malang, 2016.

[2] Shawar, Bayan Abu, and Eric Atwell. A comparison between ALICE and Elizabeth chatbot systems. University of Leeds, School of Computing research report. 2002.

[3] Fatnuriyah Martin. "Perancangan I_Bot (Sistem Informasi Chatterbot) Menggunakan AIML Berbasis Program O Untuk Akses Sistem Informasi PMDFT", Universitas Brawijaya. 2012.

[4] Mahdiyah, Evfi, and Yanti Andriyani. "Analisa Algoritma Pemahaman Kalimat Pada ALICE ChatBot Dengan Menggunakan Artificial Intelligence Markup Language (AIML)." Seminar Nasional dan Rapat Tahunan (SEMIRATA), 2013; Vol 1.1.

[5] Indah, Lusy. Implementasi Mesin ALICE untuk Informasi Penerimaan Mahasiswa Baru (PMB). Malang: Universitas Muhammadiyah Malang; 2016. 